\title{
Influence of CDW Recycled Aggregate on Drying Shrinkage of Mortar
}

\author{
Paulo Roberto Lopes Lima, Monica Batista Leite \\ Civil and Environmental Engineering Post-Graduate Program, State University of Feira de Santana, Feira de Santana, Brazil \\ Email: lima.prl@pq.cnpq.br
}

Received October 18, 2011; revised November 20, 2011; accepted December 5, 2011

\begin{abstract}
The use of fine recycled aggregates as raw material in the production of mortars appears as a good alternative to minimize waste disposal, so as to reduce natural resources consumption and to find and supply suitable substitutes for natural aggregates. However, the use of this alternative material in a safe way must be carried out by a wide investigation of its long term behavior. In this way, this paper will examine the mechanical strength, physical properties and drying shrinkage of mortar, which use recycled fine aggregates that have originated from construction and demolition waste (CDW) containing mortar (55\%), ceramic (26\%) and concrete (16\%). Two natural mortars, made with natural sand, were produced with cement/sand ratios of 1:4 and 1:8 (by weight) and a fixed consistency index of $260 \pm 10 \mathrm{~mm}$. Recycled mortar was produced with $50 \%$ of substitution rate, in volume, of natural aggregate by recycled one. Results show that recycled mortars present higher total porosity, absorption rate and drying shrinkage than reference mortar.
\end{abstract}

Keywords: Recycled Mortar; Construction and Demolition Waste; Drying Shrinkage; Recycled Aggregate

\section{Introduction}

The construction industry consumes considerable natural and physical resources and as such has a significant impact on the environment $[1,2]$. However, how the construction sector plays a significant role in economic development in every country it is necessary ensuring sustainability without reducing the rate of construction activities or bringing some of them to a halt.

The use of recycled aggregate from concrete waste had been investigated by several authors [3-5] and represents a good alternative to minimize two important environmental impacts of sector: use of non-renewable natural resources and waste disposal. However, in Brazil, the main components of rubble collected from demolished buildings or construction activities are mortar waste, ceramic brick and tile. The waste concrete usually represents a minor part of construction and demolition waste (CDW). The effects of mortar and ceramic particles on properties of recycled aggregate are less addressed in literature. It is believed that their high water absorption capacity can jeopardize the final properties of concretes and mortars. In fact, comparative study on behavior of recycled mortar show that mortars containing recycled aggregates from ceramic brick developed lower compressive and bond strength with respect to the mortar containing concrete waste [6]. Miranda [7] has reported that the distribution of the pore sizes generated by the presence of high amount of fines in the mixtures plays a higher effect on drying shrinkage than that of the porosity introduced by the effective water cement/ratio. This phenomenon has been observed in recycled mortar [8].

The aim of this study is to investigate the influence of recycled fine aggregate from $\mathrm{CDW}$ in the production of mortar. The properties of hardened mortars are illustrated and the analysis of the influence of recycled fine aggregates on the absorption, compressive strength and shrinkage drying of the mortar is presented.

\section{Experimental Program}

\subsection{Materials}

The characterization of Portland cement used (CP V ARI ASTM Type III) is shown in Table 1. Tap water supplied by the local water supply company was used on the mixtures.

Construction and demolition waste (CDW) sourced from a building demolition site at Feira de Santana City (Northeast of Brazil) was crushed into pieces using a jaw crusher and screened in $4.8 \mathrm{~mm}$ sieves to produce recycled fine aggregate (RFA). The composition of RFA is shown in Figure 1.

The natural fine aggregates used were $70 \%$ of one fine quartz sand (NFA1) and $30 \%$ of one medium river quartz sand (NFA2). The physical properties of the aggregates are shown in Table 2 and the granulometric distribution 
curves are shown in Figure 2. As RFA is a very porous aggregate the method proposed by Leite [9] was used to determine your specific gravity and water absorption rate.

\subsection{Mortars Mix Proportions}

Two series of mortars were produced with the cement/ sand ratios of $1: 4$ and 1:8 (by weight), to evaluate the influence of cement content on recycled mortar. The substitution rate of natural fine aggregate by recycled aggregate, in volume, was $50 \%$. The workability of the mortars was determined through the flow table test according to Brazilian Standard, NBR 13276, and was fixed a consistency index of $260 \pm 10 \mathrm{~mm}$.

The recycled mortars were produced with the same mix proportions as the reference mortar except for those minor adjustments in weight proportions of aggregates that were made to compensate the differences in density between natural and recycled fine aggregates. The recycled aggregate also required an increase in mixing water

Table 1. Results of the characterization of cement.

\begin{tabular}{|c|c|c|}
\hline \multicolumn{2}{|l|}{ Properties (test method) } & Results \\
\hline \multicolumn{2}{|c|}{ Material finer than \# $75 \mu \mathrm{m}$ (NBR MB 3432/91) } & $0.0 \%$ \\
\hline \multicolumn{2}{|c|}{ Initial set time (NBR NM 65/03) } & $2 \mathrm{~h} 45 \mathrm{~min}$ \\
\hline \multicolumn{2}{|c|}{ Final set time (NBR NM 65/03) } & $3 \mathrm{~h} 30 \mathrm{~min}$ \\
\hline \multicolumn{2}{|c|}{ Expansibility (NBR MB 3435/91) } & $0.133 \mathrm{~mm}$ \\
\hline \multicolumn{2}{|c|}{ Specific gravity (NBR NM 23/01) } & $3.13 \mathrm{~g} / \mathrm{cm}^{3}$ \\
\hline \multirow{3}{*}{$\begin{array}{l}\text { Compressive strength } \\
\text { (NBR 7215/1996) }\end{array}$} & 1 day & $33.9 \mathrm{MPa}$ \\
\hline & 3 days & $34.9 \mathrm{MPa}$ \\
\hline & 7 days & $40.2 \mathrm{MPa}$ \\
\hline
\end{tabular}

content for compensating water absorption of recycled aggregate to achieve the same workability as the reference mortar [6]. The mix proportions and consistency index of the mortars are given in Table 3.

Mortars mixtures were carried out in a mechanical mixer of $5 \mathrm{dm}^{3}$. After removing the specimens from the molds they were cured at the humid chamber at $23^{\circ} \mathrm{C} \pm$ $2^{\circ} \mathrm{C}$ and relative humidity of $100 \%$ until they have reached an age of 28 days.

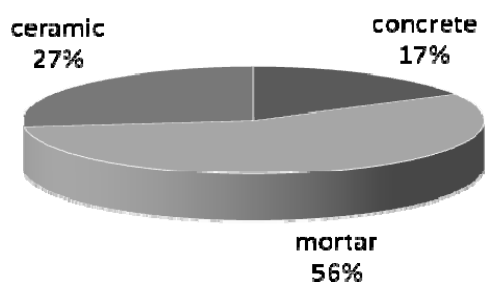

Figure 1. RFA composition.

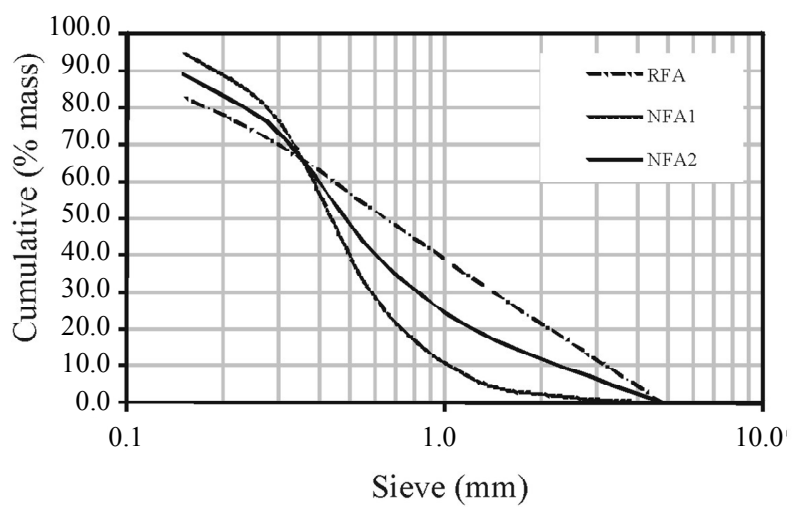

Figure 2. Granulometric analysis of aggregates.

Table 2. Results of the characterization of aggregates.

\begin{tabular}{|c|c|c|c|}
\hline Properties (test method) & NFA1 & NFA2 & RFA \\
\hline Maximum size aggregate (mm) (NBR NM 248/03) & 1.2 & 2.4 & 4.8 \\
\hline Fineness (NBR NM 248/03) & 1.68 & 2.90 & 2.56 \\
\hline Specific gravity $\left(\mathrm{kg} / \mathrm{dm}^{3}\right)$ & $2.59^{1}$ & $2.55^{1}$ & $2.55^{2}$ \\
\hline Bulk density $\left(\mathrm{kg} / \mathrm{dm}^{3}\right)(\mathrm{NBR} 7251 / 82)$ & 1.53 & 1.39 & 1.27 \\
\hline Water absorption rate $(\%)$ & $0.1^{3}$ & 0.2 & $19.3^{2}$ \\
\hline Fines content (\%) (NBR NM 46/03) & 1.7 & 0.7 & 10.4 \\
\hline $\begin{array}{l}{ }^{1} \text { Test Method: NBR NM 52/03 } \\
{ }^{2} \text { Test Method: Leite [9] }\end{array}$ & ${ }^{3}$ Test Method: NBR NM 30/03 & & \\
\hline
\end{tabular}

Table 3. Mortar mixture proportions $\left(\mathrm{kg} / \mathrm{m}^{3}\right)$.

\begin{tabular}{|c|c|c|c|c|c|c|c|c|c|}
\hline \multirow{2}{*}{ Mixtures } & \multirow{2}{*}{ Cement: Sand } & \multirow{2}{*}{ w/c Ratio } & \multirow{2}{*}{ Cement } & \multicolumn{3}{|c|}{ Aggregates } & \multirow{2}{*}{ Water } & \multirow{2}{*}{$\begin{array}{l}\text { Additional } \\
\text { Water }\end{array}$} & \multirow{2}{*}{$\begin{array}{l}\text { Consistency Index } \\
\text { (mm) }\end{array}$} \\
\hline & & & & NFA $1(60 \%)$ & NFA $2(40 \%)$ & RFA & & & \\
\hline NM1 & \multirow{2}{*}{$1: 4$} & \multirow{2}{*}{0.70} & 381 & 914 & 609 & 0 & 267 & 0 & 256 \\
\hline RM1 & & & 381 & 457 & 305 & 754 & 267 & 44 & 264 \\
\hline $\mathrm{NM} 2$ & \multirow{2}{*}{$1: 8$} & \multirow{2}{*}{1.44} & 201 & 966 & 644 & 0 & 290 & 0 & 260 \\
\hline RM2 & & & 201 & 483 & 322 & 797 & 290 & 57 & 261 \\
\hline
\end{tabular}




\subsection{Test Procedures}

Compressive Strength and Absorption and Porosity Tests

Eleven specimens (cylinders of $50 \mathrm{~mm}$ in diameter $\times$ $100 \mathrm{~mm}$ in height) were cast for each mortar mixture, using manual compaction. Four samples were cast for compression tests at the age of 7 and 28 days according to NBR 7215. And, three samples were cast for the determination of absorption rate and total porosity, at the age of 28 days, according to NBR 9778.

Drying shrinkage

One set of three plates of $10 \mathrm{~mm}$ of thickness, $150 \mathrm{~mm}$ in width and $500 \mathrm{~mm}$ in length were cast from each mortar mixture to evaluate drying shrinkage. Plates were cast in steel molds and removed from them at an age of 24 hours. The plates were marked (Figure 3) and immersed in water at $23^{\circ} \mathrm{C} \pm 2{ }^{\circ} \mathrm{C}$ until they have reached an age of 28 days.

After cure, the length and weight measurements of each specimen have been taken at 1, 2, 3, 4, 5, 6, 7, 14, 21,28 days and at 8,12, 16 and 20 weeks. The drying shrinkage test were carried out at relative humidity of $50 \% \pm 4 \%$ and temperature of $23^{\circ} \mathrm{C} \pm 2{ }^{\circ} \mathrm{C}$.

The drying shrinkage of any plate is calculated at any age after initial period of air storage with the Equation (1):

$$
\varepsilon=\frac{\Delta L}{L} 10^{6}
$$

where,

$\varepsilon=$ drying shrinkage of specimen $(\mu \varepsilon)$,

$\Delta L=$ difference between the length reading of specimen at any age and the initial length, and

$L=$ initial length reading at an age of 28 days after curing (mm).

\section{Results and Discussion}

\subsection{Compressive Strength, Absorption Rate and Voids}

Table 4 presents the results for compressive strength, absorption rate and porosity. In parenthesis, coefficient of variation in percentage.

The absorption and porosity of recycled mortars (RM1 and RM2) are much higher than that for natural mortars (NM1 and NM2). This is due to the greater porosity of recycled aggregate, which is composed of porous materials as tiles, bricks and mortar.
The Figure 4 shows the evolution of strength of mortars. The influence of recycled aggregate on compressive strength is dependent of cement content and water-cement ratio of mortar. To rich mixture (NM1) the substitution of $50 \%$ of natural aggregate results in reduction of $8.1 \%$ compressive strength at 28 days. To poor mixture (NM2), however, it is verified an increment of about $15.0 \%$ of strength when the recycled aggregate is added. The main reason is that the strength of the paste greatly increases at low water/cement ratio and the recycled aggregate is the fragile element. To high water/cement ratio the strength of aggregate has a minor influence on mortar strength and the reverse mechanics can appears due to a better bond strength between recycled aggregate and cement paste [10]. According Katz [11] the maintenance of the compressive strength with increasing fine aggregate replacement can be explained by high levels of cement

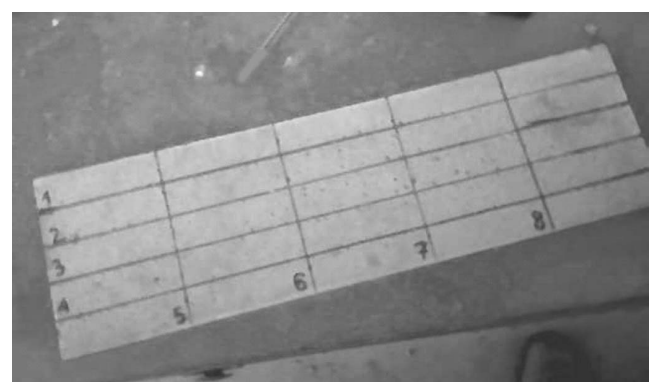

Figure 3. Plate of mortar marked along the length to be measured.

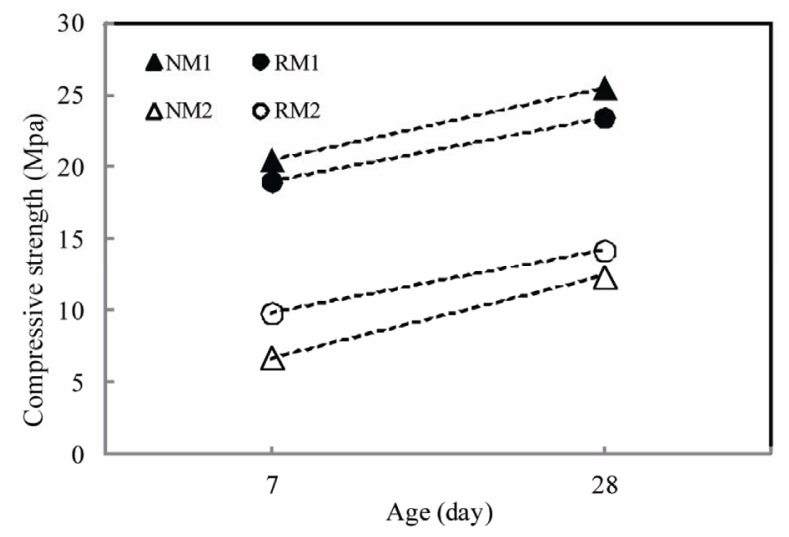

Figure 4. Evolution of compressive strength of natural and recycled mortar.

Table 4. Results of the compressive strength, absorption and porosity tests.

\begin{tabular}{|c|c|c|c|c|c|}
\hline Properties & Age & NM1 & RM1 & NM2 & RM2 \\
\hline \multirow{2}{*}{$\mathrm{fc}(\mathrm{MPa})$} & 7 days & $20.4(0.4)$ & $19.0(0.2)$ & $6.7(0.2)$ & $9.8(1.1)$ \\
\hline & 28 days & $25.5(0.6)$ & $23.4(0.4)$ & $12.3(1.7)$ & $14.2(0.9)$ \\
\hline Density $\left(\mathrm{kg} / \mathrm{dm}^{3}\right)$ & & $2.46(0.02)$ & $2.52(0.01)$ & $2.56(0.01)$ & $2.55(0.02)$ \\
\hline Absorption (\%) & 28 days & $10.4(0.40)$ & $15.3(0.1)$ & $13.11(0.2)$ & $17.4(0.7)$ \\
\hline Porosity (\%) & & $20.3(0.7)$ & $27.8(0.1)$ & $25.1(0.4)$ & $30.8(1.1)$ \\
\hline
\end{tabular}


(both hydrated and non-hydrated) that reach as much as $25 \%$ of its weight, increasing the total amount of cement in the mix. To recycled concrete, a minor influence of addition of recycled aggregate on compressive strength with increment of w/c ratio is also observed. For concretes with a w/c ratio equal to 0.82 , the cement matrix around the aggregate particles has a lower compressive strength than the matrix of concrete with a w/c ratio equal to 0.49 that presented rupture by breakage of the aggregate [12]. Corinaldesi and Moriconi [6] associate the increment of strength of recycled mortar to the shape of aggregate particles that contributes to improving bond strength at the interface between aggregate and surrounding cement paste.

\subsection{Drying Shrinkage}

Drying shrinkage of natural and recycled mortars was determined at various time intervals and is presented in Figure 5 as average values of four measures from three specimens. A large difference between recycled mortar and reference mortar can be observed, independent of the cement/sand ratio. The use of $50 \%$ of recycled aggregate substitution rate results on increasing drying shrinkage by $700 \mu \varepsilon$ to $2000 \mu \varepsilon$. This is associated to greater porosity and absorption of recycled aggregate when compared with natural aggregate. Similar results were observed by Miranda and Selmo [7].

The weight loss is more important for recycled mortars than for natural mortars, as shown in Figure 6.

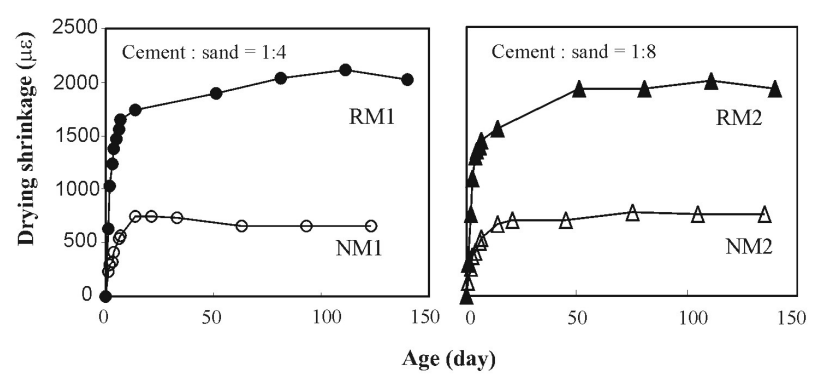

Figure 5. Drying shrinkage vs age.

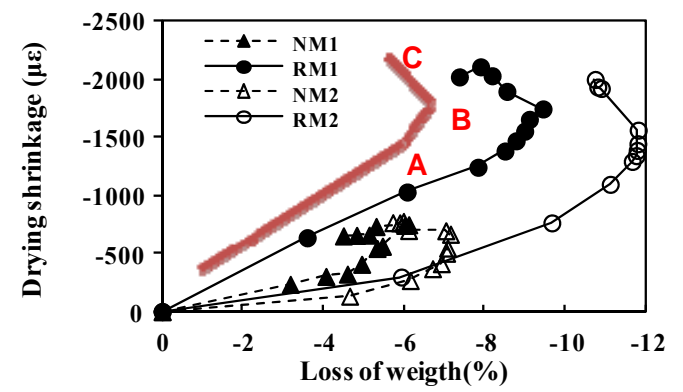

Figure 6. Drying shrinkage deformation vs loss of weight.
It can be observed three zones [8]: a first zone OA starting at the origin corresponds to the shrinkage due to the departure of water from the pores; a second zone between $\mathrm{A}$ and $\mathrm{B}$ corresponds to the shrinkage due to the departure of water from the capillaries; and a third zone corresponds to a gain of weight which that can be connected to carbonation and explained by the high porosity of these recycled mortars in the ratio of $27 \%$ and $30 \%$, which makes the penetration of carbonic gas possible.

It is verified in Figure 6 that recycled mortars shown more weight loss in zone OA. This result indicates a higher presence of water in the pores of recycled aggregates due to major porosity of this material that stores more water than natural aggregate. The zone $\mathrm{AB}$ represented a weight loss of about $2 \%$ for all mixtures which indicate that the recycled aggregate has small influence on formation of capillaries voids.

\section{Conclusion}

For two mortars, which differed in cement/sand ratio, tests have shown the following effects of recycled aggregate use:

- The addition of $50 \%$ of recycled aggregate increases the porosity and absorption significantly, when compared with reference mortar;

- To richer mixture (1:4), there is a decrease in compressive strength which is about $8 \%$ for the mortar with $50 \%$ of recycled aggregate. The other way round, mortar mixture with cement/sand ratio 1:8 showed a gain in compressive strength with $50 \%$ of recycled aggregate;

- Recycled aggregate increase drying shrinkage independent of the mortar matrix, which is linked with greater porosity and absorption of recycled aggregate. The weight loss evaluation indicates: 1) a higher presence of water in the pores of recycled aggregate due to higher porosity of this material that stores more water than natural aggregate; 2) recycled aggregate has small influence on formation of capillaryies voids.

\section{Acknowledgements}

The authors would like to thank FAPESB for the financial support in this research development.

\section{REFERENCES}

[1] I. Z. Bribián, A. V. Capilla and A. A. Usón, "Life Cycle Assessment of Building Materials: Comparative Analysis of Energy and Environmental Impacts and Evaluation of the Eco-Efficiency Improvement Potential," Building and Environment, Vol. 46, No. 5, 2011, pp. 1133-1140.

[2] B. Norton and H. Skates, "Technologies for Sustainable Buildings," World Renewable Energy Congress 6, Elsevier, New York, 2000. 
[3] L. Evangelista and J. Brito, "Durability Performance of Concrete Made with Fine Recycled Concrete Aggregates," Cement \& Concrete Composites, Vol. 32, No. 1, 2010, pp. 9-14.

[4] C. J. Zega, Y. A. Villagran-Zaccardi and A. A. Di Maio, "Effect of Natural Coarse Aggregate Type on the Physical and Mechanical Properties of Recycled Coarse Aggregates," Materials and Structures, Vol. 43, 2010, pp. 195-202. doi:10.1617/s11527-009-9480-4

[5] G. F. Kheder and S. A. Al-Windawi, "Variation in Mechanical Properties of Natural and Recycled Aggregate Concrete as Related to the Strength of Their Binding Mortar," Materials and Structures, Vol. 38, 2005, pp. 701-709.

[6] V. Corinaldesi and G. Moriconi, "Behaviour of Cementitious Mortars Containing Different Kinds of Recycled Aggregate," Construction and Building Materials, Vol. 23, No. 1, 2009, pp. 289-294.

[7] L. F. R. Miranda and S. M. S. Selmo, "CDW Recycled Aggregate Renderings: Part I-Analysis of the Effect of Materials Finer than $75 \mu \mathrm{m}$ on Mortar Properties," Construction and Building Materials, Vol. 209, 2006, pp.
615-629. doi:10.1016/j.conbuildmat.2005.02.025

[8] H. A. Mesbah and F. Buyle-Bodin, "Efficiency of Polypropilene and Metallic Fibres on Control of Shrinkage and Craking of Recycled Aggregates Mortars," Construction and Building Materials, Vol. 13, No. 8, 1999, pp. 439-447.

[9] M. Leite, "Evaluation of the Mechanical Properties of Concrete Made with Aggregates from Construction and Demolition Waste," PhD Thesis, Porto Alegre, 2001.

[10] H. J. Chen, T. Yen and K. H. Chen, "The Use of Building Rubbles in Concrete and Mortar," Journal of the Chinese Institute of Engineers, Vol. 26, No. 2, 2003, pp. 227-236. doi: 10.1080/02533839.2003.9670773

[11] A. Katz, "Properties of Concrete Made with Recycled Aggregate from Partially Hydrated Old Concrete," Cement and Concrete Research, Vol. 33, No. 5, 2003, pp. 703-711.

[12] P. R. L. Lima, M. B. Leite and E. Q. Santiago, "Recycled Lightweight Concrete Made from Footwear Industry Waste and CDW," Waste Management, Vol. 30, No. 6, 2010, pp. 1107-1113. 